\title{
Estimating the effect of optimizing anticancer drug vials on medical costs in Japan based on the data from a cancer hospital
}

Koichi Matsuo ${ }^{1,2^{*}}$ D, Hisanaga Nomura ${ }^{3}$ (D), Masanobu Uchiyama ${ }^{1}$, Motoyasu Miyazaki ${ }^{1,2}$ and Osamu Imakyure ${ }^{1,2}$

\begin{abstract}
Background: The substantial increase in the use of expensive anticancer drugs has been accompanied by an increase in the amount of disposing residual liquid from drug preparations. Many Western countries, including the United States, have implemented drug vial optimization (DVO) to prevent the waste of anticancer drugs and have reported the reductions in the total drug costs. This study was designed to estimate the expected reduction in spending on anticancer drugs by Japanese cancer hospitals when DVO was implemented instead of individual preparations and to test the effectiveness of this approach.

Methods: We investigated the doses of drugs used and quantity specifications for individually prepared vials for patients who received anticancer drug treatment in December 2017 at the Outpatient Treatment Center of the National Cancer Center Hospital East. Based on these findings, we calculated the total quantity of each drug used on a given day, and the minimum cost for preparation of the number of specified combinations corresponding to the total cost (DVO preparation). Based on the differences in these two costs, we estimated the economic impact of implementing DVO.

Results: While the cost for anticancer drugs for the 1-month study period was US\$3,305,595 (US\$1= $\backslash 110)$ for individual preparations, the estimated cost for DVO preparations was US\$3,092,955, equivalent to a reduction of US\$212,640.

Conclusions: Based on these study results, implementation of DVO-based preparation of injectable anticancer drugs in Japan in 2017 would have resulted in saving approximately US\$460 million. This calculation revealed the need for the Japanese government to modify the methods employed to calculate drug costs in the insurance system and develop policies for the proper and optimal use of medical resources.
\end{abstract}

Keywords: Drug vial optimization (DVO), Reduction cost, Vial-sharing, Drug waste, Anticancer drug

\footnotetext{
* Correspondence: ko1matsuo@fukuoka-u.ac.jp

'Department of Pharmacy, Fukuoka University Chikushi Hospital, Fukuoka 818-8502, Japan

${ }^{2}$ Department of Pharmaceutical and Health Care Management, Faculty of Pharmaceutical Sciences, Fukuoka University, Fukuoka, Japan

Full list of author information is available at the end of the article
}

(c) The Author(s). 2020 Open Access This article is licensed under a Creative Commons Attribution 4.0 International License, which permits use, sharing, adaptation, distribution and reproduction in any medium or format, as long as you give appropriate credit to the original author(s) and the source, provide a link to the Creative Commons licence, and indicate if changes were made. The images or other third party material in this article are included in the article's Creative Commons. licence, unless indicated otherwise in a credit line to the material. If material is not included in the article's Creative Commons licence and your intended use is not permitted by statutory regulation or exceeds the permitted use, you will need to obtain permission directly from the copyright holder. To view a copy of this licence, visit http://creativecommons.org/licenses/by/4.0/ The Creative Commons Public Domain Dedication waiver (http://creativecommons.org/publicdomain/zero/1.0/) applies to the data made available in this article, unless otherwise stated in a credit line to the data. 


\section{Background}

Japan's anticancer drug market exceeded US\$10 billion in 2017, and this value is expected to increase to approximately US $\$ 13$ billion in 2020 [1]. The significant increase in the use of expensive anticancer drugs has been accompanied by an increase in the amount of residual liquid discarded from drug preparations [2-5]. Under the Japanese insurance system, the final medical cost is calculated as the total amount of vial usage for each drug used for each patient. For this reason, the Guidance on Safe Multiple Use of Injectable Anticancer Drugs was issued by Japan's Ministry of Health, Labour and Welfare in 2018. However, the current medical insurance system provides little financial incentive for medical institutions to implement drug vial optimization (DVO). Consequently, drug waste accumulates, leading to unnecessary medical spending. In Japan and other countries, reducing unnecessary costs associated with the disposal of anticancer drugs is a key factor in the optimization of medical resources. By contrast, many Western countries, including the United States, have implemented DVO to increase the efficiency of anticancer treatment, resulting in decreases in the total drug costs [6-9]. However, because of the aforementioned reasons, there has been little progress in reducing drug waste in Japan. Maintaining the current method of disposing large amounts of expensive anticancer drugs in Japan is inefficient in terms of medical economics. Therefore, this study aimed to estimate the potential cost savings for the implementation of DVO in cancer hospitals in Japan. To the best of our knowledge, analyses of this issue have rarely been reported.

\section{Methods}

\section{Aim}

The aim of this study was to estimate cost savings that could be realized with the implementation of DVO preparation in cancer hospitals in Japan.

\section{Design and setting of the study}

We investigated treatment regimens, drug doses, and quantities of drugs using vial specifications for individual patients who received anticancer treatment in December 2017 at the Outpatient Treatment Center of the National Cancer Center Hospital East. These data were generated using the anonymized per-patient doses of anticancer drugs extracted from the hospital electronic medical records and imputed in the regimen management system. The amount calculated using this method represented the total level of vial usage of each drug used in Japan, in where DVO had not been implemented. We then used these data to calculate the total quantities and costs of each drug used on a daily basis along with the minimum cost for specified individual combinations of drugs prepared using DVO. The amount calculated using this method represented the level of drug consumption when DVO is implemented and the minimum amount is reached. The difference between in these two costs reflected the estimated cost reduction expected from the implementation of DVO.

\section{The characteristics of the participants}

All patients treated at the Outpatient Treatment Center of National Cancer Center Hospital East during the survey period were included in this study.

\section{Statistical analysis}

Microsoft Office Excel 2016 (Microsoft, Redmond, WA, USA) was used to compile and analyze the data in this study; however, no statistical analysis was performed.

\section{Ethics approval}

Because this report only examined the quantities of anticancer drugs used and thus, the study was a nonmedical study that did not require an ethical review or approval under "Ethical Guidelines for Medical and Health Research Involving Human Subjects" in Japan.

\section{Results}

The investigation involved 7 diagnostic departments, 2354 patients, and 3346 drugs. Table 1 presents a summary of the quantity of the top 5 most used drugs.

The total number of vials used for each drug was then utilized to estimate the vial usage of each drug under the assumption that DVO was implemented in the manner described in Table 2.

Based on these estimates, the drug costs for individual vials and DVO preparation were US\$3,305,595 and US\$3,092,955, respectively, resulting in a difference of US $\$ 212,640$ for the 1 -month study period. Table 3 presents the differences in the total cost between individual vials and DVO preparation for the top 10 drugs.

These results revealed the annual amounts, i.e., US\$39, 667,140 and US\$37,115,460, for individual vials and DVO preparation, respectively, with a difference of US\$2,551,680.

\section{Discussion}

The study results indicated that annual spending on all anticancer drugs in Japan could be reduced by $6.4 \%$ by implementing DVO. Based on the estimated size of the Japanese injectable anticancer drug market in 2017 of US $\$ 7,227,096,043$, the annual savings would be US $\$ 464$, 899,573 , thus representing savings of $3.7 \%$ for entire anticancer drug market [1]. This percentage cannot be neglected when considering limited the limitations on the medical resources. 


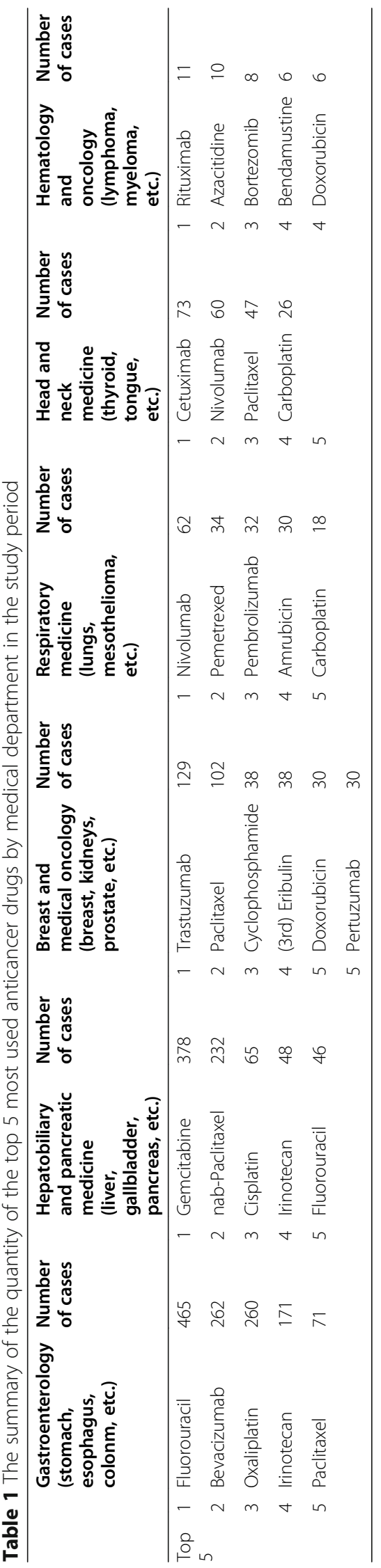




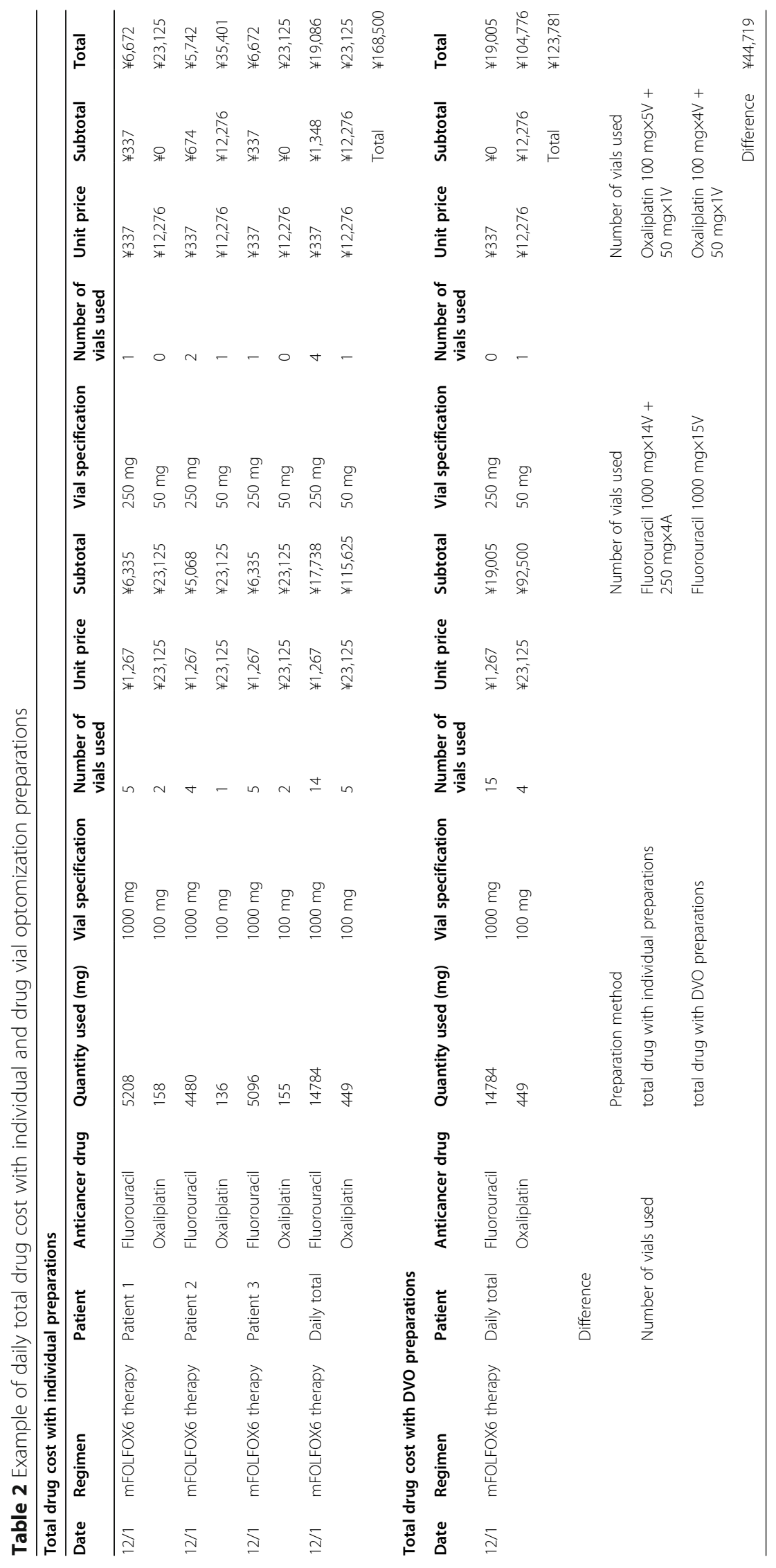




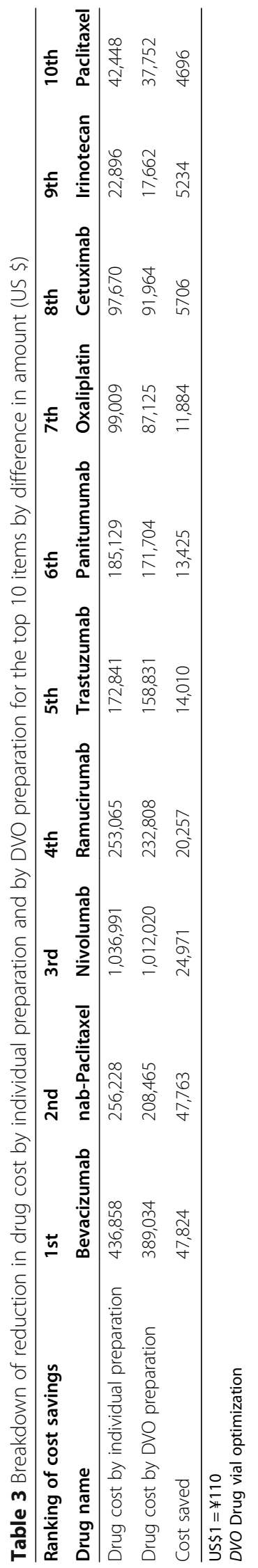


Our estimation revealed that for therapy with specific cytotoxic and molecular targeted agents, which are expensive drugs used in large quantities, noticeable cost reductions would be expected. These results are consistent with the findings of other similar studies $[4,5,10$, 11]. Further, some frequently used cytotoxic agents and molecular targeted agents might account for $70 \%$ of disposal costs [10]. Recently, expensive drugs such as molecular targeted agents and immune checkpoint inhibitors have entered the market, leading to significant increases in the total drug expenditures [12-17]. The use of such drugs is expected to increase further in the future; thus, the economic impact of DVO is expected to increase accordingly.

Because of the differences in the medical insurance systems, few economic studies related to DVO have been conducted in Japan. However, a study in the United Kingdom did report that repeated use of vials showed significant cost savings, especially for molecularly-targeted drugs [11]. In this study, vials could be used repeatedly is possible for 7 days. However, our estimates were based on the number of vials needed to achieve same-day-only repeated use. Thus, the potential economic savings in Japan could exceed the estimation specified in this study. Further, two Italian investigations found that disposal costs accounted for 4.8 and $8.3 \%$ of the annual costs of anticancer drug therapy, respectively $[10,18]$. These percentages are in line with our finding of $6.4 \%$, and in terms of medical economics, we believe that solving the problem of disposal costs is a global issue.

In the medical insurance system in Japan, the presence or absence of residual liquid is not considered important by medical institutions because the patient is charged for the total amount per vial opposed to the amount of drug actually used. Hence, the implementation of DVO, which would reduce the use of medical resources, has not progressed. With Japan's method of calculating drug costs, the implementation of DVO means that only the cost of using a closed system drug transfer device would be borne by the medical institution. Disposal costs associated with residual liquid from drug preparations in Japan will continue to increase more rapidly than observed in Europe and the United States, in which DVO is widely implemented.

Unlike the United States, Japan does not use multidose vials, and the drug packages insert only mention singledose vials. Furthermore, until the release of the Guidance on Safe Multiple Use of Injectable Anticancer Drugs in 2018, it was mandated that vials should be punctured, used once, and quickly discarded. Largedose products were introduced earlier in Europe and the United States than in Japan based on the premise of DVO [6]. The use of large-dose products is particularly economical for general-purpose products, and the development of an environment in Japan in which such products can be used will also be useful in reducing costs [19].

On the contrary, it was suggested in recent theoretical economic models that the use of standard oversized vials of cancer drugs that are very large to be used by a single person represents the cause of drug waste [20,21]. To reduce the waste of anticancer drugs, special attention should be paid to giant vials, and consideration should be given to manufacturing more suitable vials when necessary.

A limitation of this study was that the cost estimation was performed using data collected from a single facility, although it was a leading cancer hospital in Japan. In addition, the drugs used and patients' backgrounds were not considered. Additionally, because the annual figure was estimated using data for a single month, the data may not strictly reflect the annual figure.

\section{Conclusions}

According to our estimates, the implementation of DVO in Japan could lead to potential annual cost savings of US\$464,899,573. Currently, DVO has not been promoted because of the lack of incentives in the Japanese medical insurance claims system. However, given the sizable amount of medical waste, institutional reform as a national policy is urgently needed.

Abbreviation

DVO: Drug vial optimization

\section{Acknowledgments}

Not applicable.

\section{Authors' contributions \\ $\mathrm{KM}$ and $\mathrm{HN}$ conceived the idea and design of the study. KM, MM, and MU analyzed and interpreted the data. MM and MU collected and assembled the data. KM and OI drafted the article. KM critically revised the paper for important intellectual content. All authors have read and approved the final manuscript.}

\section{Funding}

The authors received no financial support for the research, authorship, and publication of this article.

\section{Availability of data and materials}

The data supporting the findings of this study can be made available by the corresponding author upon reasonable request.

\section{Ethics approval and consent to participate}

This study did not qualify as medical research involving humans because it only used anticancer drug doses for one institution and no data that would identify individual patients were used. Therefore, in accordance with "Ethical Guidelines for Medical and Health Research Involving Human Subjects"

promulgated by Japan's Ministry of Health, Labour and Welfare, and Ministry of Education, Culture, Sports, Science and Technology an ethical review was not required.

Consent for publication

Not applicable. 


\section{Competing interests}

The authors declare no potential conflicts of interest with respect to the research, authorship, and publication of this article.

\section{Author details}

'Department of Pharmacy, Fukuoka University Chikushi Hospital, Fukuoka 818-8502, Japan. ${ }^{2}$ Department of Pharmaceutical and Health Care Management, Faculty of Pharmaceutical Sciences, Fukuoka University, Fukuoka, Japan. ${ }^{3}$ Department of Pharmacy, National Cancer Center Hospital East, Chiba, Japan.

Received: 14 July 2020 Accepted: 14 October 2020

Published online: 09 November 2020

\section{References}

1. IQVIA. In-house aggregated based on 2017 JPM. Reprinted with permission. https://www.iqvia.com/insights/the-iqvia-institute/reports. Accessed 5 June 2020.

2. Bach PB, Conti RM, Muller RJ, et al. Overspending driven by oversized single dose vials of cancer drugs. BMJ. 2016;352:1788. https://doi.org/10.1136/bmj.i.788.

3. Lien K, Cheung MC, Chan KKW. Adjusting for drug wastage in economic evaluations of new therapies for hematologic malignancies: a systematic review. J Oncol Pract. 2016;12:e369-79.

4. Clark L, Castro AP, Fortes AF, Santos F, et al. Ideal vial size for bortezomib: real-world data on waste and cost reduction in treatment of multiple myeloma in Brazil. Value Health. 2011;14:82-4.

5. Sheffield KM, Beyrer JK, Watson IA, et al. Minimization of olaratumab drug waste using real-world data. Am J Health Syst Pharm. 2017;74:832-42.

6. Suzuki $S$, Gibar P, Yu B, et al. Current status of drug vial optimization use to prevent waste associated with injectable anticancer agents. J Oncol Pharm Pract. 2019;25:244-6.

7. Iwamoto T. Drug vial optimization (DVO) for anticancer drugs. Gan To Kagaku Ryoho. 2017;44:353-6.

8. Gopisankar MG, Wahlang J, Jagtap V, Sarkar C, et al. Cancer chemotherapy drug wastage in a tertiary care hospital in India-a 3-month prospective and 1-year retrospective study. Br J Clin Pharmacol. 2019;85:2428-35.

9. Hess $\mathrm{LM}, \mathrm{Cui} \mathrm{ZL}$, Li XI, et al. Drug wastage and costs to the healthcare system in the care of patients with non-small cell lung cancer in the United States. J Med Econ. 2018;21:755-61.

10. Fasola G, Aprile G, Marini L, et al. Drug waste minimization as an effective strategy of cost-containment in oncology. BMC Health Serv Res. 2014;57. https://doi.org/10.1186/1472-6963-14-57.

11. Smith RSV. A 2-year retrospective review of vial sharing options for the compounding of cytotoxics. Eur J Hosp Pharm. 2015;22:161-4.

12. Sullivan R, Peppercorn J, Sikora $K$, et al. Delivering adordable cancer care in high-income countries. Lancet Oncol. 2011;12:933-80.

13. Khayat D. Innovative cancer therapies: putting costs into context. Cancer. 2012;14:2367-71.

14. Smith TJ, Hillner BE. Bending the cost curve in cancer care. N Engl J Med. 2011:364:2060-5.

15. Elkin EB, Bach PB. Cancer's next frontier addressing high and increasing costs. JAMA. 2010;303:1086-7.

16. Gilbar PJ. A further strategy to combat the high price of anticancer drugs. Nat Rev Clin Oncol. 2017;14:629.

17. Green AK, Ohn JA, Bach PB. Review of current policy strategies to reduce US cancer drug costs. J Clin Oncol. 2020;38:372-9.

18. Fasola G, Aita M, Marini L, et al. Drug waste minimization and costcontainment in medical oncology: two-years results of a feasibility study. BMC Health Serv Res. 2008;14:70. https://doi.org/10.1186/1472-6963-8-70

19. Gillbar PJ, Chambers CR, Gilbar E. Opportunities to significantly reduce expenditure associated with cancer drugs. Future Oncol. 2017;13:1311-22.

20. Truong J, Cheung MC, Mai H, et al. The impact of cancer drug wastage on economic evaluations. Cancer. 2017;123:3583-90.

21. Liran $\mathrm{O}$, Prus J, Noa G, et al. A real-world analysis of cancer drug wastage due to oversized vials. J Am Pharm Assoc. 2018;58:643-6.

\section{Publisher's Note}

Springer Nature remains neutral with regard to jurisdictional claims in published maps and institutional affiliations.

\section{Ready to submit your research? Choose BMC and benefit from:}

- fast, convenient online submission

- thorough peer review by experienced researchers in your field

- rapid publication on acceptance

- support for research data, including large and complex data types

- gold Open Access which fosters wider collaboration and increased citations

- maximum visibility for your research: over $100 \mathrm{M}$ website views per year

At BMC, research is always in progress.

Learn more biomedcentral.com/submissions 